Proceedings of the 2006 Winter Simulation Conference

L. F. Perrone, F. P. Wieland, J. Liu, B. G. Lawson, D. M. Nicol, and R. M. Fujimoto, eds.

\title{
SYSTEM DYNAMICS SIMULATION OF THE EXPANSION OF THE PANAMA CANAL
}

\author{
Humberto R. Alvarez A. \\ Dario Solis \\ Technological University of Panama \\ P. O. Box 0819-070289 \\ Panama, PANAMA
}

\author{
Arnoldo R. Cano S. \\ Panama Canal Master Plan \\ Coordinating Team \\ Panama Canal Authority \\ Building 632, 2nd floor \\ Balboa, PANAMA
}

\author{
Serge Sala-Diakanda \\ Dept. of Industrial Engineering and \\ Management Systems \\ University of Central Florida \\ Orlando, Florida, 32816 U.S.A.
}

\begin{abstract}
The expansion of the Panama Canal could be the largest project attempted by the Republic of Panama in its 100 years of existence. The objective of this simulation study is to use the Canal Expansion project to develop and demonstrate how more precise and applied concepts involving the complex decision making processes can be used in large "system of systems". It is an attempt to explain the decision making process for complex systems, and to develop a model that will help with the political, social and economic decision making processes involved in this very large project. Challenges involved in this research initiative included developing the parametric expressions that explain the dynamical intricacies and validation of the expansion project. A hybrid system is also proposed by using different types of simulation and mechanisms such as neural networks to incorporate some of the societal/political parameters.
\end{abstract}

\section{INTRODUCTION}

The Panama Canal <http://panama.canal> as shown in Figure 1 is a 50-mile long system of navigation channels and locks, which allows vessels to navigate between the Pacific and the Atlantic Oceans through and over the Isthmus of Panama, by means of man-made Gatún Lake, 30 meters above sea level. The Canal was cut through one of the narrowest parts of Panama, and uses gravity-operated locks to raise and lower vessels between sea level and Gatún Lake. It requires about eight to ten hours for an average ship to transit between the Pacific and Atlantic locks.

Since its construction in 1914, the Panama Canal has been a key element in the development of the world's shipping industry. It currently carries over 4 percent of world's traded goods (Panama Canal Authority 2005), and it is an important competitor in some very important shipping routes. For example, the Canal currently handles about $16 \%$ of the United States maritime trade, and more than
$25 \%$ of the containerized trade between North East Asia and the East Coast of the United States (Lozano 2005). For the Republic of Panama, the Canal has driven the growth of the terminal cities of Panama and Colon, through the development of a conglomerate of interrelated services and industries surrounding the Canal, including transshipment ports, railways, bunkering, ship repairs, banking, insurance and tourism, among others.

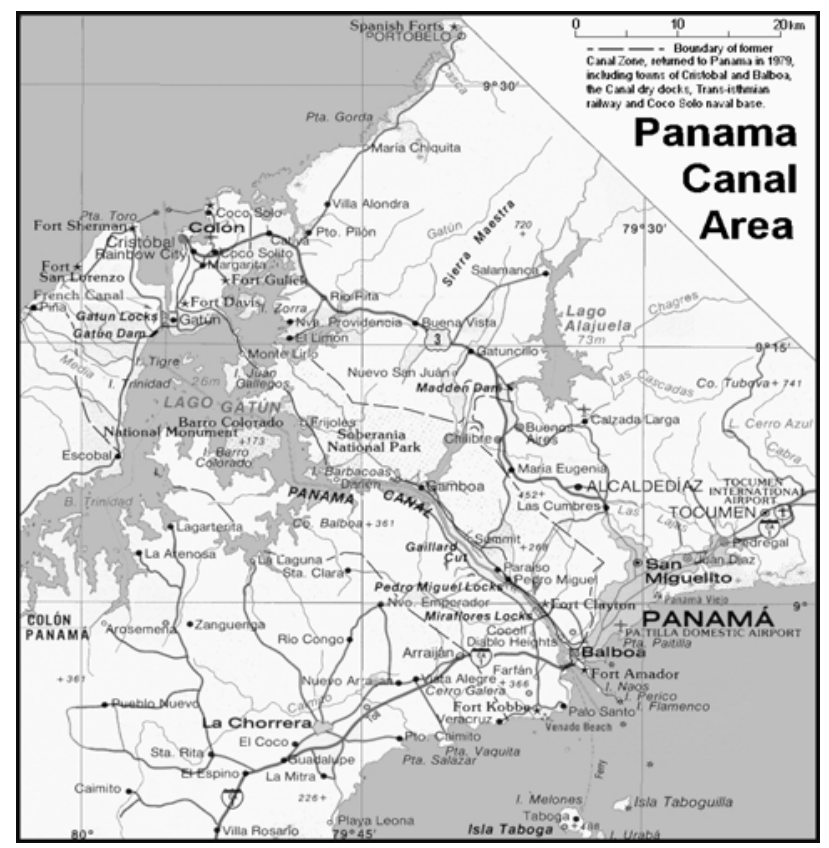

Figure 1: The Panama Canal Area

The Panama Canal has been subject to great pressure due to changes in the maritime industry. Changes in transportation trends, including the growing use of containers and shipping services with fixed routes and itineraries, have been pressing the Canal for more capacity and a more reliable service, reducing waiting and transit times. At the same time, the increasing use of vessels that cannot transit 


\section{Alvarez, Solis, Cano, and Sala-Diakanda}

the Canal, especially by the Container segment, is pressing it to modernize and expand its locks and facilities to maximize the number of transits and the amount of cargo through the Canal.

Currently the Canal is operating at almost $90 \%$ of its maximum sustainable capacity (Lozano 2005; Franzese, Abdenur, Starks, Botter, and Cano 2004) which will limit its ability to provide a quality service and to capture the increasing demand within the next five to eight years. Additionally, port operators at both sides of the Canal are betting on larger and more efficient Pospanamax ships and making multimillion dollars investments in cranes, container yards and other infrastructure to accommodate these vessels (Sandoval 2005).

Due to these pressures, the Panama Canal Authority has proposed an expansion project, known as the Third Set of Locks. This project would add a third "lane" to the Canal's existing two-lane locks. The project would consist of two new single-lane locks parallel to the existing ones, one in the Atlantic side and one in the Pacific side, with the capacity to handle larger vessels. The Panama Canal Authority is also considering the use of a system of water saving basins for reusing water in the new locks, so they would consume less water than the existing locks.

However, the decision to expand the Panama Canal is not for the Panama Canal Authority to make. According to the Panamanian Constitution, any decision regarding the expansion of the Panama Canal has to be approved through a national referendum. Thus, the expansion plan will be put through a consultation process before a decision is made.

Interest groups have emerged with differing positions regarding this project. Groups in favor emphasize the impact that the Canal has on the Panamanian economy. According to figures from the National Accounting Office of the Republic of Panama (Sandoval 2005), the Canal has been constantly growing during the last 10 years, making a significant contribution to the national economy. For instance, contributions to the Panamanian government total over $\$ 1$ billion in the last five years. Additionally, for every dollar the Canal generates, more than $\$ 1.25$ is generated by the local economy supporting and supported by the Canal. Since the expansion should nearly double the cargo through the Canal within its first ten years of operation, the direct impact of the project on the economy would be significant. Additionally, during the estimated 6 years of construction, employment generation and other social and economic impacts would be of great importance.

On the other hand, groups opposing the expansion argue that there will be an increase in fresh water requirements due to the operation of the new locks, and that this will require the construction of new reservoirs in the Canal watershed, with significant environmental impact on the surrounding lands, including farming and agricultural areas within the Canal watershed. Another argument presented by opposing groups is that the cost of the project has been estimated to be between 5 to 8 billion dollars, with some estimates over 10 billions. It is argued that the construction of the project would require long term financing, which could significantly limit the availability of funds to solve other important social and economic problems in the country.

Given that the expansion would be the largest infrastructure project ever attempted in Panama since the construction of the Canal, the goal of developing a model with the objective of understanding the effect that the different variables concerning the expansion project have on the different elements involved in this complex project was attempted. To accomplish the above, we developed a systemic model showing the relationships and effects of the expansion on Panama, not only from an economic point of view, but also considering the social and environmental impacts. Our initial task was to study the impact of the expansion of the Panama Canal on the country in terms of complex systems theory, and to develop a model that will reveal the necessary political, social, environmental and economic decisions concerning this mega project.

To achieve the objectives, the authors selected System Dynamics as a tool to dynamically emulate these variables and relationships. System dynamics has been identified as an approach to introduce a more dynamic thinking structure to the fluctuating aspects of decision-making (Winch 1998, Forrester 1961, Giaglis 2000, and Sterman 2000).

As part of the attempt in developing the proposed model, special attention was taken in the model validation process. The validation of a system dynamics model is concerned with two criteria (Klabbers 2000, Dutta and Roy 2002, Wittenberg 1992, and Larsen and Lomi 1999). First, the model must generate behavior that does not significantly differ from that of the real system. Second, a model can be said to explain the behavior of a system if it reflects the real causal relations of the system. Consequently, the extent to which the model is useful is more the function of the user than of the developer.

To build the model, a methodology called COMPRAM was used. This is a methodology developed with the objective of handling complex societal problems. A complex societal problem can be defined as real life problems that present a dynamic behavior. COMPRAM, which stands for COMplex societal PRoblems Analysis Methodology, is a prescriptive framework to analyze, guide and predict complex societal problems. The method indicates the necessary meta-steps that a multidisciplinary team should follow to define, describe, and solve complex System Dynamics problems. More information on the method can be found on DeTombe (DeTombe 2001). 


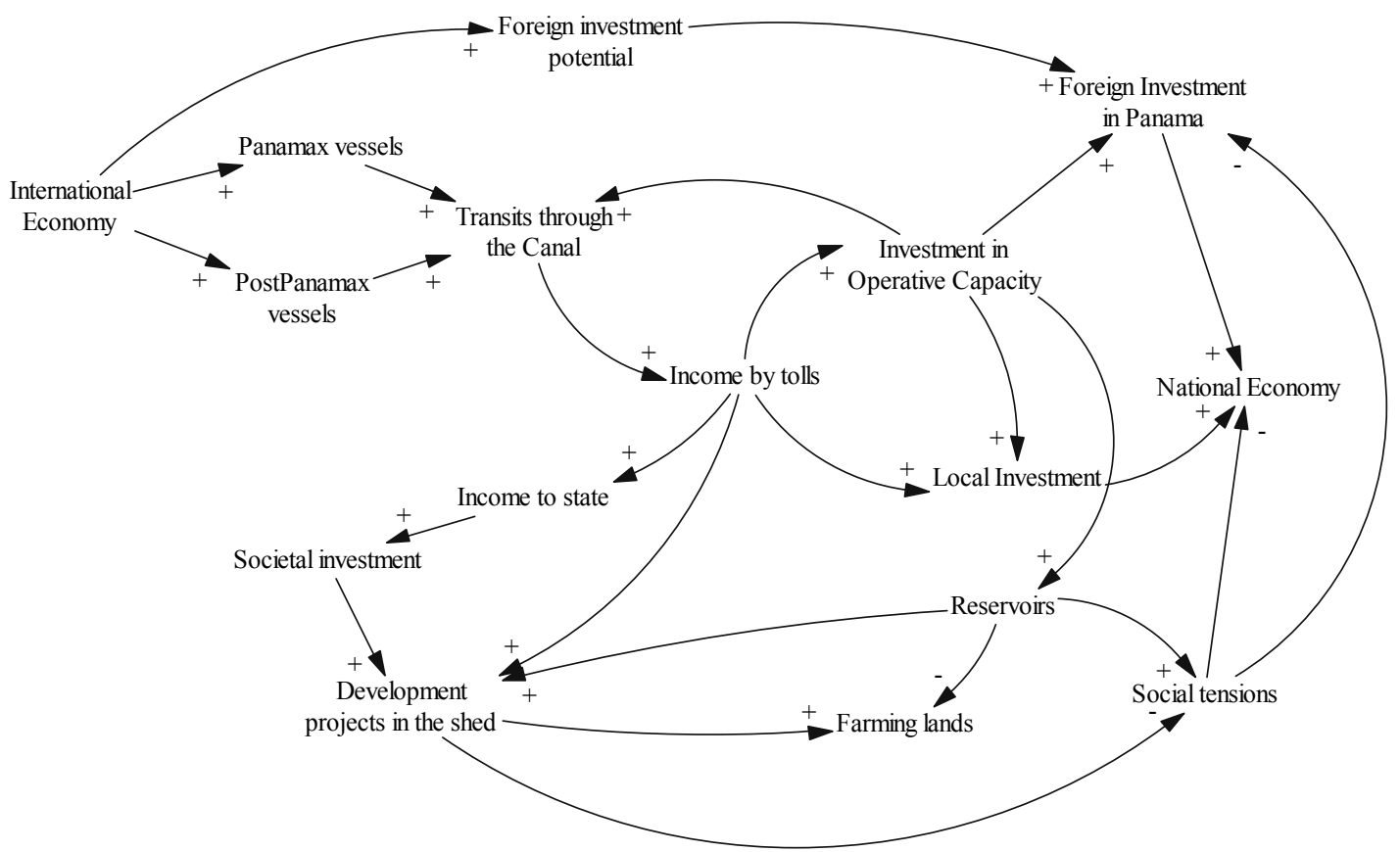

Figure 2: Causal Model

\section{THE MODEL}

This paper will not go into details about the modeling process. However, it is important to mention that several meetings with personnel from the Panama Canal Authority and with other relevant actors involved in the project were conducted. Information from the operation and other relevant aspects of the Canal was also reviewed. Since much of this information is still confidential, the current models use approximations for some data, based on the behavior of the original data presented by the Canal Authority and scaled to it.

The Causal Model is shown in Figure 2, and shows that as the number of transits increase, the earnings due to tolls should also increase. This fact will, in turn, increase the need for more operational capacity which correspondingly increases the transit capacity. As the transit capacity rises, the need for additional water also increases, with the rate of this increase being a function of the type of watersaving technology applied. In other words, the need of additional water for operations is proportional to the capacity, but moderated by the type of technology. This implies that any growth in capacity will require some additional water from the existing reservoirs, and may or may not require additional reservoirs. This need contrasts with the increase in farming lands as a result of social investments by the regional government due to the rise in transits resulting from the increased operating capacity of the Canal.

Finally, two dynamic sub-models were derived from the Causal Model. Figure 3 shows the Dynamic Model cor- responding to the operation of the Canal and its influences on different aspects such as state income and social investment. As seen, net income for the state is the difference between total income from transits reduced by operating expenses, investment in operating capacity and social investment.

It has input variables, such as the estimated forecast of cargo crossing the Canal as a function of the type of vessel and the revenues and costs for each cargo ton, depending on the type of vessel. Another input is "Time to expansion", which is a switch variable. Since the simulation time has been set to 25 years, values of this variable that are less than this time represents the date when the expansion would begin operating. Values greater than 25 years simulate scenarios without expansion.

The last sub-model, the Dynamic Model for Reservoirs, is shown in Figure 4. It simulates the effect that any increase on capacity have on farming land. This model uses "Time to expand the Canal" as an input variable since the rate of use of farming land will be a function of both social investment and the expansion of the Canal. Validation of both the model and sub-models was originally conducted by means of analyzing the causalities by experts from the Canal Authority and the research group.

Additionally, several test runs were conducted using simulated data similar in structure to the data provided by the Panama Canal Authority and comparing resulting behavior with the predicted behavior defined by analysts at the Canal Authority and other organizations. 


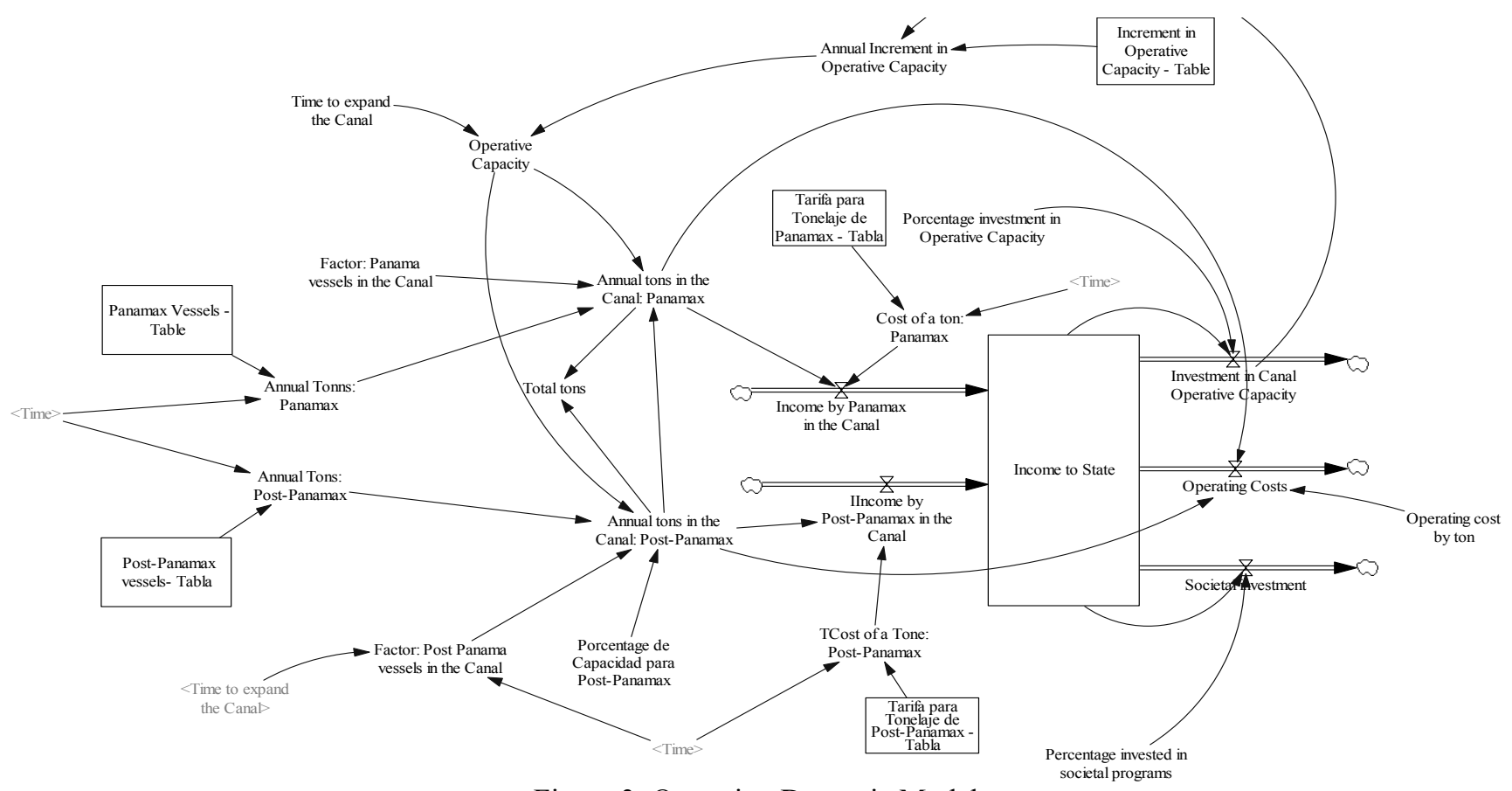

Figure 3: Operation Dynamic Model

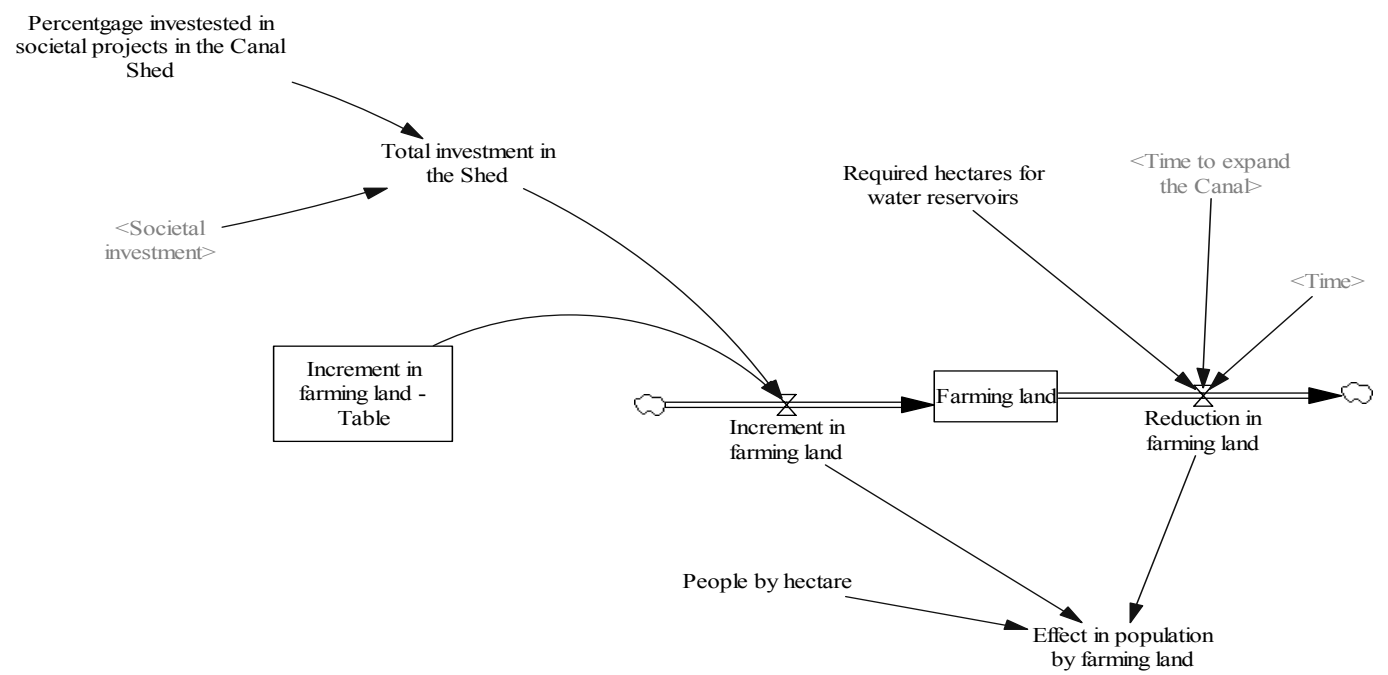

Figure 4: Reservoirs Dynamic Model

The graphs in Figure 5 show the comparison of different variables based on two scenarios: Expansion and No Expansion. Table 1 list the basic assumptions for the different scenarios.

Table 1: Assumption for the Different Scenarios Scenario

Time to expansion

\begin{tabular}{ll}
\hline \multicolumn{1}{c}{ Expansion } & No Expansion \\
\hline 10 years & 100 years \\
$15 \%$ of annual & $5 \%$ of annual \\
income & income
\end{tabular}

The 15\% investment in the case of expansion was assumed since the Canal Authority has to cover the financial burden of the expansion. In the No Expansion scenario, it was assumed $5 \%$ since only incremental improvements can be made due to the limited capacity of the Canal. 


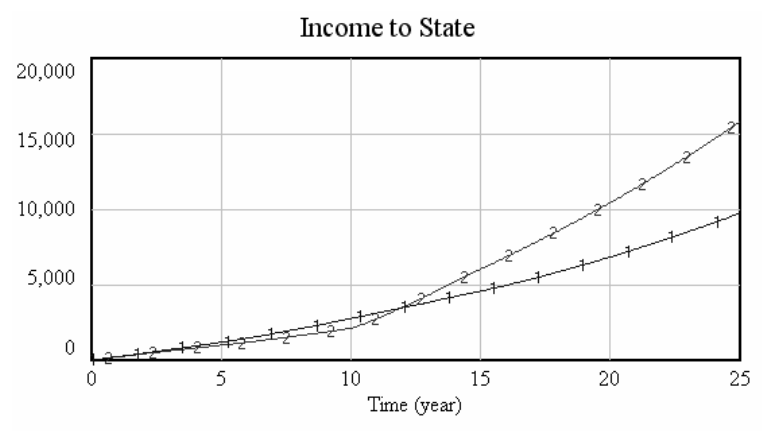

Income to State : No Expansion $1 \quad \begin{array}{lllllll}1 & 1 & 1 & 1 & 1 & 1 & 1\end{array}$ Income to State : Expansion $\begin{array}{lllllllllll}2 & 2 & 2 & 2 & 2 & 2 & 2 & 2 & 2 & \text { Mdollars }\end{array}$

(Fig. 5a)

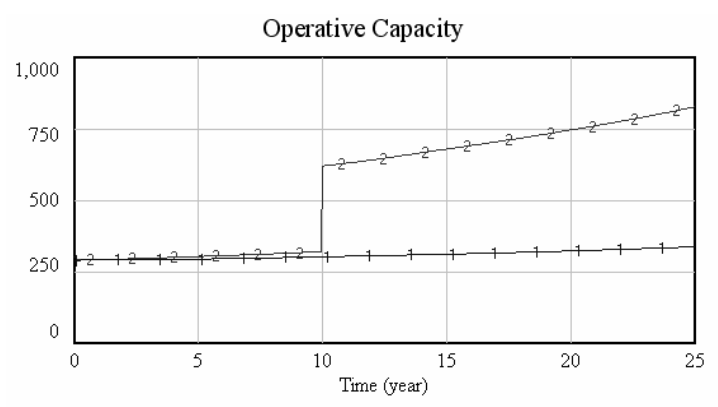

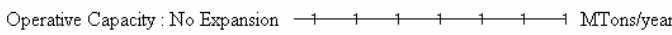
Operative Capacity : Expansion $\begin{array}{lllllllll}2 & 2 & 2 & 2 & 2 & 2 & 2\end{array}$ MTons/year

(Fig. 5b)

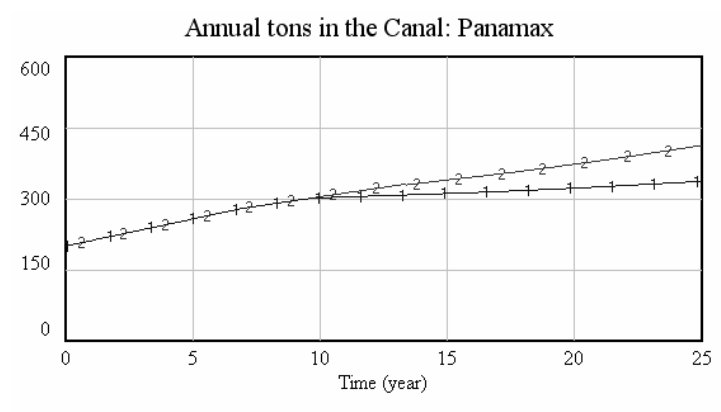

"Annual tons in the Canal: Panamax" : No Expansion $1,1,1,1$ MTons/year "Annual tons in the Canal: Panamax" : Expansion $\begin{array}{llllll}2 & 2 & 2 & 2\end{array}$ MTons/year

(Fig. 5c)

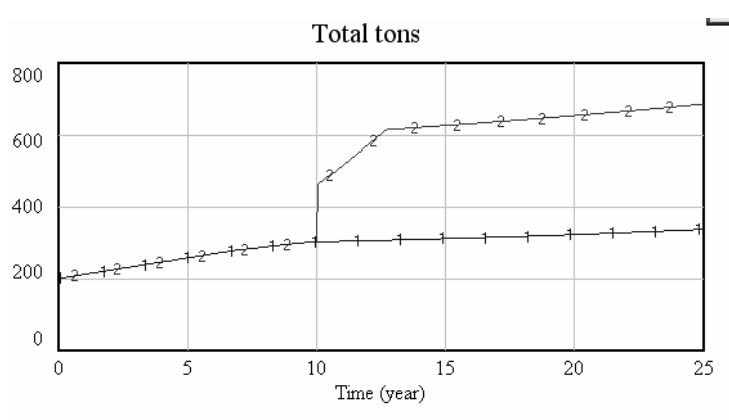

Total tons : No Expansion $\begin{array}{lllllllllllll}1 & 1 & 1 & 1 & 1 & 1 & 1 & 1 & 1 & \text { Tons/year } \\ \text { Total tons : Expansion } & 2 & 2 & 2 & 2 & 2 & 2 & 2 & 2 & 2 & 2 & \text { Tons/year }\end{array}$

(Fig. 5d)

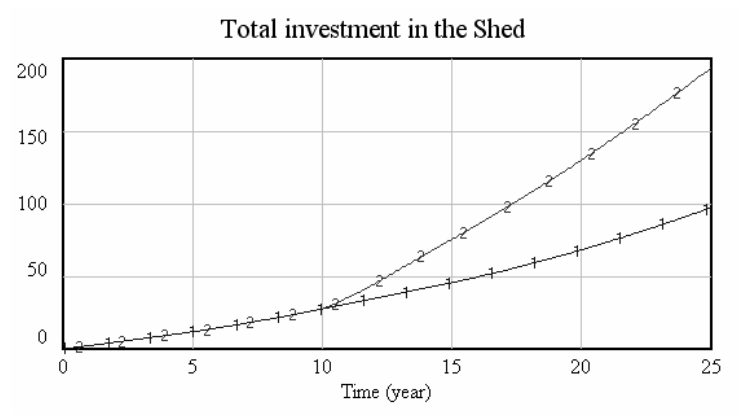

Total investment in the Shed: No Expansion $1,1,1,1-$ Mdollarlyear Total investment in the Shed: Expansion $\begin{array}{llllllll}2 & 2 & 2 & 2 & 2 & \text { Mdollarlyear }\end{array}$

(Fig. 5e)

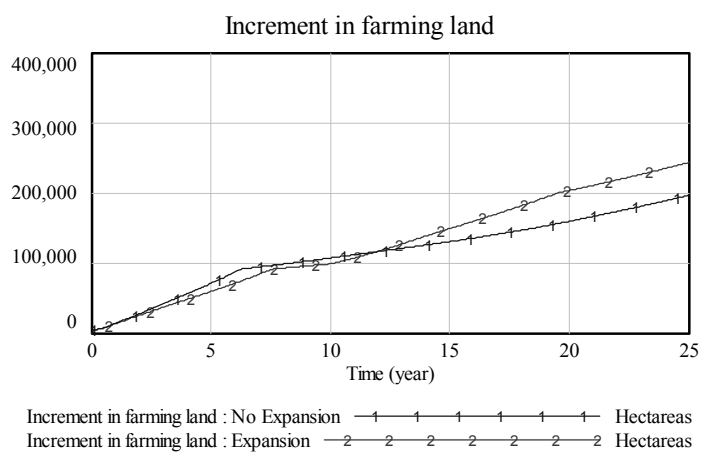

(Fig. 5f)

Figure 5: Simulation Results

Figure 5a shows that during the first five years after the expansion, the total cummulative Expansion scenario income would be less than the No Expansion scenario income. This is to be expected as in any business, the first years of operation normally have more expenses, since it must cover initial start-up costs, especially investment costs. Over time the increased tonnage, as seen in Figure $5 \mathrm{~b}$, will generate enough income to compensate for the $\mathrm{Ca}-$ nal Authority's financial expenses.

Figure $5 \mathrm{c}$ and $5 \mathrm{~d}$ show how the trend in transits depends on the Expansion and No Expansion scenarios. If the expansion occurs, one can see that while the trend in tons transported by Panamax ships tends to stabilize during expansion, there is fast growth in the amount of cargo handled due to the transits of Post-Panamax ships after the expansion is completed. If the no expansion option is selected, the trend in transits show a limited growth in the amount of tons transported, since the Canal has a limited capacity that will peak in approximately 7 years.

Figure $5 \mathrm{e}$ and $5 \mathrm{f}$ show that contrary to what is believed, the social investment in the Canal area will actually increase the probability of more development projects. This fact requires more farming land that will compete with the need for conservation of the watershed but not necessarily with the need for more reservoirs, if they were 
required to maintain the necessary water levels for the operation of the Canal.

In conclusion it is possible to affirm through the simulation analysis that the expansion of the Canal, far from causing conflicting interests, can be considered a good initiative to keep the Canal competitive while at the same time develop strategies to help relieve poverty in rural areas surrounding the Canal.

\section{NEURAL NETWORK}

As seen in figure 2, a variable that needs to be analyzed is Social Tension. Social tensions is created by social conflicts created by the discussion between groups in favor and against the project. Its effect over the model goes beyond the approval of the expansion project but also affects possible international and national investment projects in Panama.

A neural network model has been proposed to be integrated with the current system dynamics model. The objective of integrating this network is basically to capture the behavior of different actors involved in the discussion of the project and to predict how this behaviors might affect future actions in the expansion project. The neural network will use information and historical data to measure the level of acceptance of this project based on factors such as the political capital of the current government officials. In addition, the opinion of experts in sociology and political science will be used to provide other qualitative information.

\section{FUTURE EXTENSIONS}

This model has been validated by experts from both the Canal Authority and other interested organizations with simulations using values generated from data provided by the Canal Authority.

There are several follow-up activities needed to complete the project. First, the model must be run using accurate data, including accurate demand forecasts, capacity limits, water requirements and project costs, among others. There are some limitations in acquiring this data due to the confidentiality involved, but it is necessary to use the most accurate data possible for the purpose of presenting the results to the Panama Canal Authority and other interest groups. Second, it is important to develop a dynamic submodel for the aspects concerning "social tension" within the model. There is an on-going effort by the researchers in that direction. Finally, it is important to complete the dynamic sub-models including such aspects as the economic impact in Panama and other implications to national and international commerce.

\section{ACKNOWLEDGMENTS}

This research project is partially funded by the National Bureau of Science, Technology and Innovation, Panama Panama, and the support of the University of Central Florida, the Technological University of Panama, and the Panama Canal Authority.

\section{REFERENCES}

DeTombe, D. J. 2001. Compram, A Method for Handling Complex Societal Problems. European Journal of Operational Research 128(2): pp. 266-261.

Dutta, A., and R. Roy. 2002. System Dynamics. ORMS Today 29(3): pp. 30-35.

Forrester, J. W. 1961. Industrial Dynamics. The M. I. T. Press - Massachusetts Institute of Technology and John Wiley \& Sons, Inc., U. S. A.

Franzese, L. A., L. O. Abdenur, D. Starks, R. C. Botter, and A. Cano.. 2004. Simulating the Panama Canal, Present and Future. Proceedings of the 2004 Winter Simulation Conference. pp. 1835 - 1838.

Giaglis, G. M. 2001. A Taxonomy of Business Process Modeling and Information Systems Modeling Techniques. The International Journal of Flexible Manufacturing Systems 13(2): pp. 209-228.

Klabbers, J. H. G. 2000. Learning as Acquisition and Learning as Interaction. Simulation \& Gaming 31(3): pp. 380-406.

Larsen, E. R., and A. Lomi. 1999. Resetting the Clock: A Feedback Approach to the Dynamics of Organizational Inertia, Survival and Change. Journal of the Operational Research Society 50(4): pp. $406-221$.

Lozano, L. 2005. Still Going Strong. The Journal of Commerce 6(48): p. 24.

Panama Canal Authority, Maritime Authority of Panama. 2005. Almost Full Capacity. Panama Maritime Handbook , 2005/6, $7-13$.

Sandoval, Y. 2005. The Dilemma of the Expansion Costs. Martes Financiero - La Prensa 409: January 17, pp. 24-28.

Sterman, J. D. 2000. Business Dynamics. Systems Thinking and Modeling for a Complex World. McGrawHill, New York.

The Panama Canal Area. 2000, [online]. Available via <http://lostparadise.com/maps/images /Canalzone.jpg>.[accessed January, 2006].

Winch, G. 1998. Dynamic visioning for Dynamic Environments. Journal of the Operational Research Society 49(4): pp. 354-361.

Wittenberg, J. 1992. On the Very Idea of a System Dynamic Model of Kuhnian Science. System Dynamics Review 8(1): pp 21-33. 


\section{AUTHOR BIOGRAPHIES}

HUMBERTO R. ALVAREZ A. is Professor of Industrial Engineering and Director of the Institute for Agribusiness Research and Development at the Technological University of Panama. He holds a dual degree in Industrial and Mechanical Engineering from the Technological University of Panama, and M.Sc. and Ph.D. in Industrial Engineering from the University of Missouri, Columbia. His research interests include modeling and simulation of industrial systems, system dynamics, and discrete-event simulation. His e-mail address is <humberto. alvarez@utp.ac.pa>.

DARIO SOLIS has over eighteen years of experience in simulation modeling, analysis, and engineering. He holds a dual BS degree in Electrical and Mechanical Engineering from the Technological University of Panama, an M.S. and a Ph.D. in Mechanical Engineering from the University of Iowa. He is the current Director of Research at the Technological University of Panama. His current research interest are analyzing and modeling the Panamanian Transportation System, and renewable energy systems. His e-mail address is <ario.soliseutp.ac.pa>.

ARNOLDO R. CANO S is an Industrial Engineer with an M.S. degree in Industrial and Systems Engineering from Virginia Tech. He is a member of the PANAMA CANAL AUTHORITY Master Plan Coordinating Team, and is in charge of the Canal Capacity Simulation Project. He can be contacted by email at <arcano@pancanal . com>.

SERGE N. SALA-DIAKANDA is a Ph.D. candidate in the Department of Industrial Engineering and Management Systems at the University of Central Florida. He holds a B.S in Aerospace Engineering from Embry-Riddle Aeronautical University, a M.S. in Manufacturing Processes and Systems and a Certificate in Quality Assurance from the University of Central Florida. His areas of interest include information fusion, aircraft design and distributed simulation. His e-mail address is <serge@mail.ucf. edu $>$. 